\title{
METAL COMPOSITES BEHAVIOUR UNDER BIAXIAL STRESSES
}

\author{
J. Jai* \\ Faculty of Chemical Engineering, \\ Universiti Teknologi MARA, Malaysia

\section{M.N. Berhan} \\ Faculty of Mechanical Engineering, \\ Universiti Teknologi MARA, Malaysia \\ Received 07 August 2005
}

\begin{abstract}
For this study, different volume fraction (vol.\%) of particulate alumina $\left(\mathrm{Al}_{2} \mathrm{O}_{3}\right)$ reinforced aluminium alloy (Al 6061) with 5 vol.\%, 15 vol.\% and 25 vol.\% are produced by powder metallurgy method. These samples were subjected to biaxial stresses in order to investigate the behaviour of the metal matrix composites (MMCs). Microstructure analysis on the individual sample before and after loading was performed under scanning electron microscopy. The small particles of $2 \mu \mathrm{m}$ in size have exhibited strong interfacial bonding with the matrix. The particles of $5 \mu \mathrm{m}$ in size have shown fractures and debonding interface. Large particles of above $20 \mu \mathrm{m}$ in size have revealed severe fractures and particles pulled out. Behavior of the MMC was explained by relating the microstructures and displacement directions of the undeformed and deformed samples. Some understandings on the behaviour of the MMCs with different vol.\% of $\mathrm{Al}_{2} \mathrm{O}_{3}$ due to biaxial stresses have been established.
\end{abstract}

Keywords: Metal matrix composites, biaxial stresses, microstructures, displacement, fracture, debonding

\section{INTRODUCTION}

Increasing demands on materials with high strength and stiffness with properties attainable at elevated temperatures have encouraged the development of the advanced composites [1]. A composite is produced when two materials are combined to produce a blend of properties that cannot be obtained in the original materials. In designing composite materials, engineers and scientists have combined various metals, ceramics and polymers to produce a new generation of materials.

MMCs are manufactured for aerospace, automotive and other structural applications. Cost saving and weight reduction are among the topics most often discussed [2]. Weight saving is the challenge of the structural designers and materials specialists, whereas cost reduction is the daily request of the manufacturing department. This leads to the development of various processing routes with various types of metal matrices and reinforcements. The available

\footnotetext{
*Corresponding author e-mail: junejai@salam.uitm.edu.my
} 
reinforcements in the market are carbides, nitrides, oxides as well as elemental materials, which are in the form of continuous fibres, chopped fibres, whiskers, platelets or particulates. The metal matrices obtainable are aluminium, magnesium, copper or titanium. The processing routes of the MMCs can be classified into three categories known as the liquid phase, solid phase and solid-liquid phases processes. Different materials of matrix and reinforcement with dissimilar processing method will give rise to different physical and mechanical properties of the produced composites.

Besides cost saving and weight reduction, knowledge on the mechanical properties of the produced MMCs is very essential for its application purposes. The mechanical properties of the MMCs are dominated by the microstructures of the reinforcing phase, matrix alloying composition and reinforcement/matrix interfacial strength. The enhancement of composite mechanical properties is not only based on the volume fraction, size, shape and spatial distribution of the reinforcement, but is also dependent upon how well the externally applied load is transferred to the reinforcing phase [3]. Strength of the MMCs is based on the load transfer from matrix to the reinforcement. There are two types of strengthening mechanisms of the MMCs, direct and indirect, depending on the characteristics of the reinforcement [4]. Direct strengthening results by the load transfer from the matrix to the reinforcement. A strong interfacial bond facilitates the load transfer. Indirect strengthening results from the influence that the reinforcement may have on the matrix microstructure such as particle size and volume fraction.

Investigations on the mechanical properties of MMCs have focused mainly on the determination of tensile characteristics. The performance of the MMC materials under compressive loading has received minor interest, in spite of the fact that MMCs have great potential in fields such as aviation and automotive components such as engine pistons, where knowledge of the compressive characteristics is essential. This research work focuses on the influence of different volume fraction of $\mathrm{Al}_{2} \mathrm{O}_{3}$ particulate reinforced aluminium metal matrix on the biaxial compressive characteristics. Behaviour of the MMCs with different volume fraction of the reinforcement experiencing biaxial compressive deformation loading has been investigated.

\section{EXPERIMENTAL WORK}

\subsection{Raw materials}

In this research work alumina $\left(\mathrm{Al}_{2} \mathrm{O}_{3}\right)$ particulate reinforced aluminium alloy ( $\mathrm{Al}$ 6061) MMCs have been investigated. Shape of the $\mathrm{Al} 6061$ was irregular while the $\mathrm{Al}_{2} \mathrm{O}_{3}$ was a combination of irregular and angular as shown in Fig. 1. Table 1 shows the chemical composition of the $\mathrm{Al}$ 6061 and the $\mathrm{Al}_{2} \mathrm{O}_{3}$.

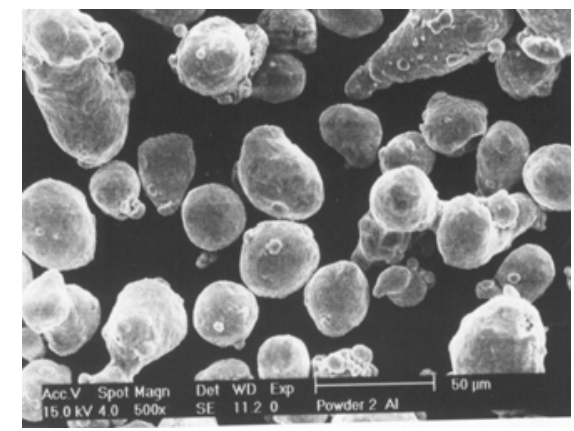

(a)

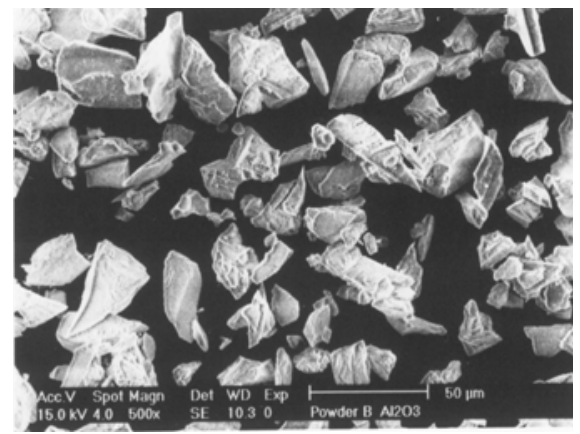

(b)

Fig. 1: Particle shape of (a) Aluminium alloy and (b) Alumina 
Table 1: Chemical composition of Aluminium alloy and Alumina

\begin{tabular}{cccc}
\hline \multicolumn{2}{c}{ Aluminium alloy $(\mathbf{6 0 6 1} \mathbf{~ A l})$} & \multicolumn{2}{c}{ Alumina $\left(\boldsymbol{\alpha}-\mathrm{Al}_{\mathbf{2}} \mathbf{O}_{\mathbf{3}}\right)$} \\
\hline Elements & Weight percent (wt \%) & Oxide & Weight percent (wt \%) \\
\hline $\mathrm{Mg}$ & 0.64 & $\mathrm{Na}_{2} \mathrm{O}$ & 0.02 \\
$\mathrm{Si}$ & 0.66 & $\mathrm{SiO}$ & 0.05 \\
$\mathrm{Fe}$ & 0.38 & $\mathrm{Fe}_{2} \mathrm{O}_{3}$ & 0.02 \\
$\mathrm{Cu}$ & 0.19 & $\mathrm{TiO}_{2}$ & 0.01 \\
$\mathrm{Cr}$ & 0.17 & $\mathrm{MgO}$ & 0.01 \\
$\mathrm{Zc}$ & 0.11 & $\mathrm{CaO}$ & 0.03 \\
$\mathrm{Ti}$ & 0.04 & $\mathrm{~K}_{2} \mathrm{O}$ & 0.01 \\
$\mathrm{Al}$ & 83.1 & $\alpha-\mathrm{Al}_{2} \mathrm{O}_{3}$ & 99.85 \\
\hline
\end{tabular}

\subsection{Samples preparation}

$\mathrm{Al}_{2} \mathrm{O}_{3} / \mathrm{Al} 6061 \mathrm{MMCs}$ with 5 percentage volume (vol.\%), 15 vol.\%, and 25 vol. $\%$ of $\mathrm{Al}_{2} \mathrm{O}_{3}$ were produced by powder metallurgy (PM) method using hot pressing technique. Figure 2(a) illustrates the processing flow in the production of the MMCs samples. Figure 2(b) illustrates the heating profile during the consolidation process. The solidified MMCs were in the shape of a flat circular disk with $35 \mathrm{~mm}$ diameter and $5 \mathrm{~mm}$ thickness.

Figure 3 illustrates the method involved in the investigation of behaviour of the MMCs. All the samples were prepared in exactly the same way, comparisons between the undeformed and deformed samples should not be greatly affected by such uncertainties.

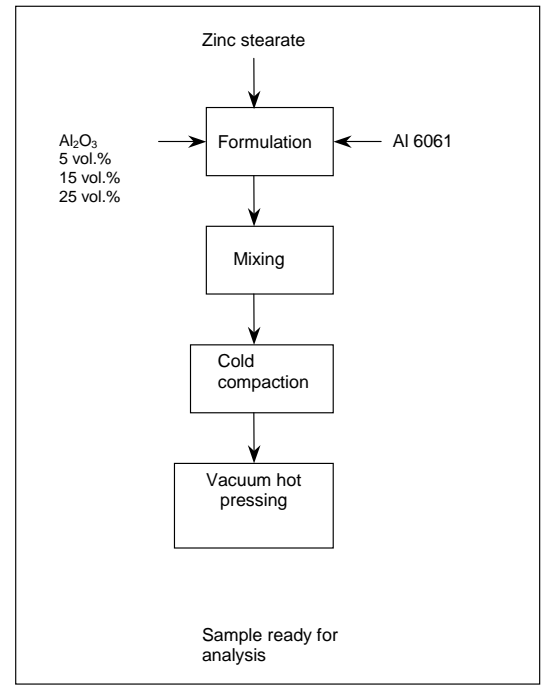

(a)

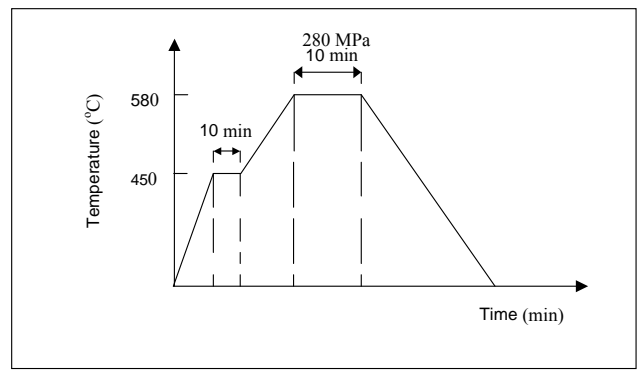

(b)

Fig. 2: Fabrication of the MMCs. (a): Processing flow in producing the MMC samples; (b): Heating profile during the vacuum hot pressing process 


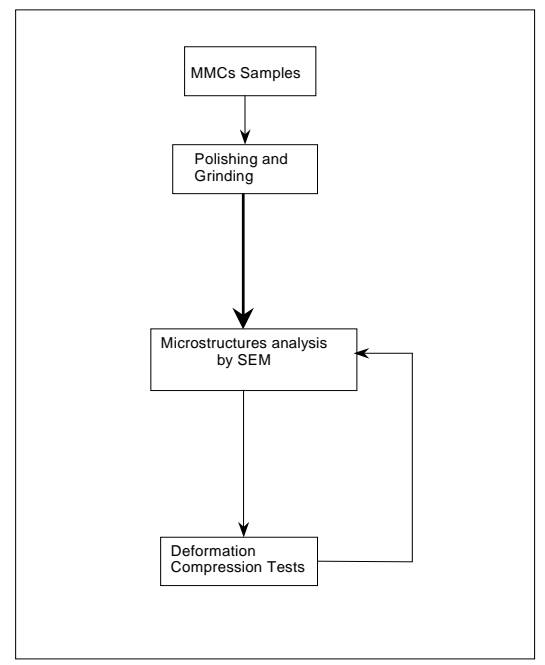

Fig. 3: Research methods in the study of behaviour of the MMCs

\subsection{Deformation test}

In this study the effect of biaxial stresses on the behaviour of the MMCs is investigated. The MMC sample was placed on top of the bottom ring plunger, which was set to a fixed condition, while the upper ring plunger was appointed to move downward at the ramp speed of 1.5 $\mathrm{mm} / \mathrm{min}$ in room condition as illustrated in Fig. 4(a). The effect of uniaxial loading introduces biaxial stresses at the bottom of the MMC samples as illustrated in Fig. 4(b). Biaxial strain gauge was cemented at the bottom of the sample which is experiencing the maximum tensile stress. The strain, stress, modulus and displacement of the samples were recorded as a function of the applied load. For this investigation the deformation test was performed in the tensile machine (Instron 100kN-UTM 5582E16). Due to samples limitation, a maximum of two samples per each test analysis were used.

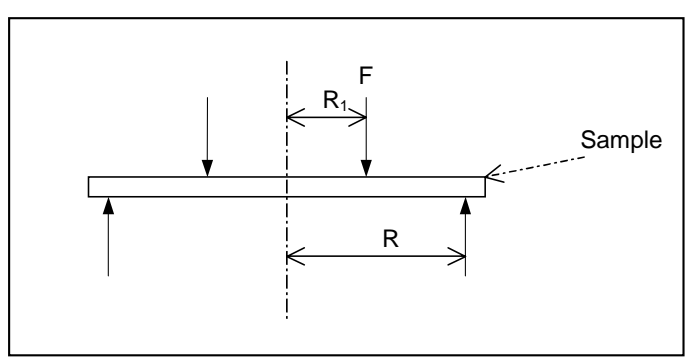

(a)

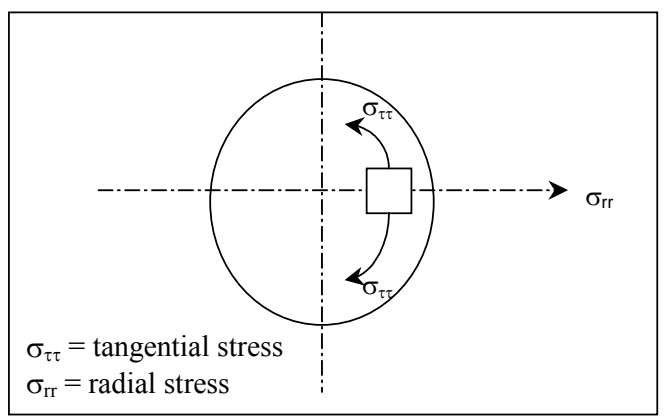

(b)

Fig. 4: (a): Diagram of circular plate sample subjected to ring load $F$, distributed around a circular sample of radius $R_{1}$; (b): The stress components at the bottom surface of the sample after compressive loading

\subsection{Microstructure analysis}

The undeformed MMC samples were observed under SEM (Philips-XL 40) for any defect such as in the matrix, individual particles and particle clusters. Similarly, the deformed samples were 
also observed under the SEM, which focuses on the bottom surface of the samples. Cracks propagation, cracks initiation, void, interface, particle clusters, individual particle and matrix cracks that exist in the microstructures were observed.

\section{RESULTS AND DISCUSSION}

\subsection{Undeformed MMC samples}

The microstructures of undeformed $5 \mathrm{vol} . \% \mathrm{Al}_{2} \mathrm{O}_{3}$ MMC samples revealed that there were small and large clusters of $\mathrm{Al}_{2} \mathrm{O}_{3}$ particles randomly distributed in the MMCs as shown in Fig. 5(a). The small number of particles within the cluster indicates small clusters while the large number of particles within the clusters shows large clusters. From the observation it has been shown that the large clusters actually consist of small particles. Most of the individual large particles were seriously fractured especially for the particles of $20 \mu \mathrm{m}$ in size and lager as shown in Fig. 5(b). Intergranular cracks and voids at the interface of $\mathrm{Al}_{2} \mathrm{O}_{3}$ particles have been observed in some of the small particles of $5 \mu \mathrm{m}$ in size as shown in Figs. 5(c) and (d). However, the voids and intergranular cracks propagations were stopped at the interface of the $\mathrm{Al}_{2} \mathrm{O}_{3}$ particles. There was no void or intergranular crack discovered in most of the small particle of $2 \mu \mathrm{m}$ in size. Minor microcracks were observed in the matrix material of 5 vol.\% $\mathrm{Al}_{2} \mathrm{O}_{3} / \mathrm{Al} 6061$.

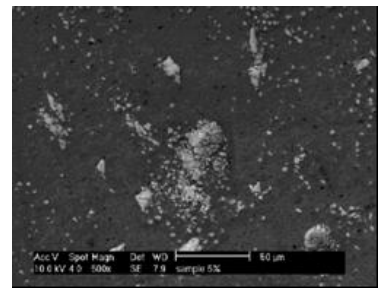

(a)

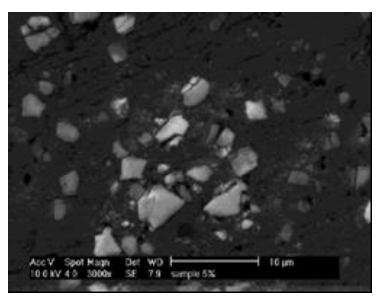

(c)

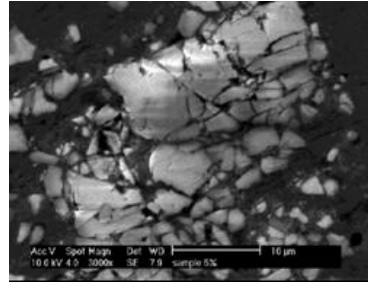

(b)

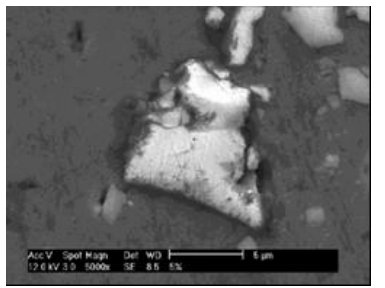

(d)

Fig. 5: Microstructures of $5 \mathrm{vol} . \% \mathrm{Al}_{2} \mathrm{O}_{3} / \mathrm{Al} 6061 \mathrm{MMCs}$ before deformation test

The microstructures of the undeformed MMC samples at 15 vol.\% $\mathrm{Al}_{2} \mathrm{O}_{3}$ showed the presence of small and large individual $\mathrm{Al}_{2} \mathrm{O}_{3}$ particles, which were randomly distributed in the MMCs as shown in Fig. 6(a). On the other hand, small and large clusters were also discovered in the MMCs. Most of the large particles shown in Figs. 6(b) and (c) were seriously fractured with parts of the particle pulled out. On the contrary, minor cracks have been observed in some of the smaller particles of $5 \mu \mathrm{m}$ in size as shown in Fig. 6(d). Microcracks were observed in the matrix, propagated along the grain boundary of the Al 6061. There was no particle pulled out observed in the large cluster. From the observation it has been shown that the large clusters consist of large and small particles. For the smaller particles of $2 \mu \mathrm{m}$ in size the same phenomena have been observed as in 5 vol. $\% \mathrm{Al}_{2} \mathrm{O}_{3} \mathrm{MMC}$ samples. 


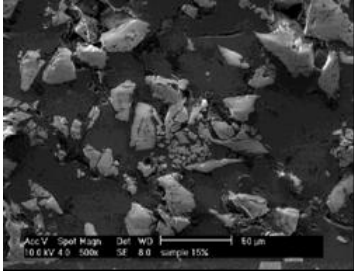

(a)

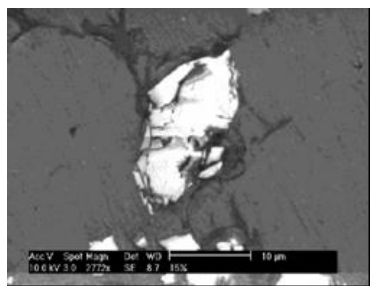

(c)

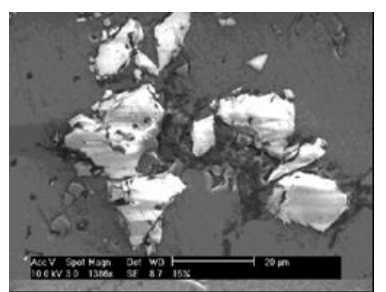

(b)

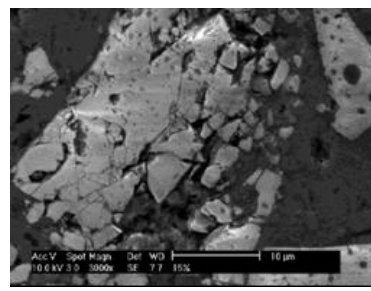

(d)

Fig. 6: Microstructures of 15 vol.\% $\mathrm{Al}_{2} \mathrm{O}_{3} / \mathrm{Al} 6061 \mathrm{MMCs}$ before deformation test

The microstructure study of the undeformed samples of 25 vol. $\% \mathrm{Al}_{2} \mathrm{O}_{3}$ shows a combination of individual particles and clusters, which were randomly distributed in the MMCs as shown in Fig. 7(a). From the observation it has been observed that the large clusters consist of large and small particles. Microcracks and debonding at interface were observed within the small cluster of the MMCs as shown in Fig. 7(b). Most of the large particles were heavily fractured with particle pulled out and voids at the interface of the particles as shown in Fig. 7(c). For the smaller particles of $25 \mathrm{vol} \% \mathrm{Al}_{2} \mathrm{O}_{3}$ MMC samples the same phenomena have been observed as in 5 vol. $\%$ and $15 \mathrm{vol} . \% \mathrm{Al}_{2} \mathrm{O}_{3} \mathrm{MMC}$ samples. Microcracks were propagated along the grain boundary of the Al 6061 matrix and stopped at the interface of a particle as illustrated in Fig. $7(\mathrm{~d})$.

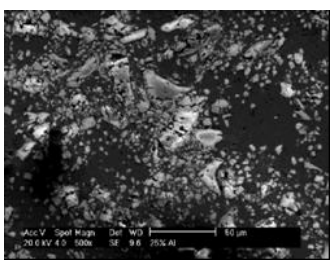

(a)

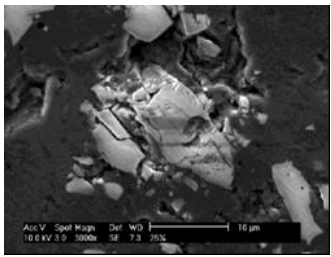

(c)

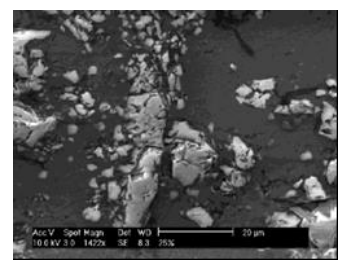

(b)

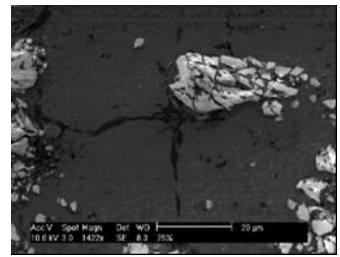

(d)

Fig. 7: Microstructures of $25 \mathrm{vol.} \% \mathrm{Al}_{2} \mathrm{O}_{3} / \mathrm{Al} 6061$ MMCs before deformation test 
There are similarities in the 5 vol. $\%, 15$ vol.\% and 25 vol. $\% \mathrm{Al}_{2} \mathrm{O}_{3}$ MMC especially on the behaviour of the small particles, large particles and small clusters. However there are slight differences in the behaviour of the large cluster. Perhaps this is due to the effect of the different vol.\% of reinforcement in the MMC.

\subsection{Compressive deformation test analysis}

Displacement data of the MMC samples have been obtained from the compressive deformation test. Figure 8 illustrates the displacement verses time curves of 5 vol. $\%, 15$ vol.\% and 25 vol.\% $\mathrm{Al}_{2} \mathrm{O}_{3}$ MMC. For 5 vol.\% $\mathrm{Al}_{2} \mathrm{O}_{3}$ MMC samples as shown in Fig. 8(a), the displacement started at around 10 seconds after compression. The displacement increases with time in the radial and tangential directions, but the displacement was more towards the radial direction. After 94 seconds of compression loading, there was a drastic drop in the displacement. For 15 vol.\% $\mathrm{Al}_{2} \mathrm{O}_{3}$ MMC samples as shown in Fig. 8(b), the displacement started at around 8 seconds after loading. The displacement increases with time in the radial and tangential directions. However at 35 and 47 seconds of the compression loading there was a sudden drop in the displacement of tangential and radial directions respectively before it stabilized. The stable displacement was more towards the radial direction. For 25 vol. $\% \mathrm{Al}_{2} \mathrm{O}_{3}$ MMC sample as shown in Fig. 8(c), the displacement of the material started after 5.5 seconds of the compression loading. The displacement increases with time in the radial and tangential directions. There was a sudden change and a drop in the displacement at 30 and 32.5 seconds of radial and tangential directions respectively before they stabilized. The stable displacement was more towards the radial direction. From the same illustration the maximum displacement length of the MMC sample can be deduced. The maximum displacement length of 5 vol. $\%, 15$ vol. $\%$ and 25 vol. $\% \mathrm{Al}_{2} \mathrm{O}_{3} \mathrm{MMC}$ samples were $28 \mathrm{~mm}, 19 \mathrm{~mm}$ and $11 \mathrm{~mm}$, respectively.

The displacement and compression load of the MMCs at the early stage of the compression test are used in the investigation of the fracture initiation. Figure 9 shows the behaviour of compression load and displacement of MMC samples at the fracture initiation. For 5 vol.\% $\mathrm{Al}_{2} \mathrm{O}_{3}$ MMC as shown in Fig. 9(a), the increase in the displacement and the drop in the compression loading were observed after 7.5 seconds of the compression loading. The displacement of the sample at this point was towards the radial direction. The displacement towards the tangential direction only started 13 seconds after loading. For the MMC sample with 15 vol.\% $\mathrm{Al}_{2} \mathrm{O}_{3}$ as shown in Fig. 9(b), the displacement started to take place with the sudden drop in the compression loading after 7 seconds. The displacement at this point was more towards the radial direction. For $25 \mathrm{vol} . \% \mathrm{Al}_{2} \mathrm{O}_{3} \mathrm{MMC}$ sample as illustrated in Fig. 9(c), at 4.5 seconds there was a drastic increase in displacement and a sudden drop in the compression load reading. At this point the displacement was more towards the tangential direction.

The displacement behaviour at the fracture initiation of 5 vol. $\%$ and 15 vol. $\% \mathrm{Al}_{2} \mathrm{O}_{3} \mathrm{MMC}$ samples is more towards the radial direction. On the other hand, the fracture initiation of 25 vol. \% $\mathrm{Al}_{2} \mathrm{O}_{3} \mathrm{MMC}$ sample is more towards tangential direction. Ductility of the MMC samples can be explained from the displacement behaviour due to deformation loading. Brittleness of the materials indicated by the time taken for the MMC samples to reach the maximum displacement before fracture. The ductile material requires a long time to reach its maximum displacement before fracture. The $25 \mathrm{vol} . \% \mathrm{Al}_{2} \mathrm{O}_{3} \mathrm{MMC}$ is the most brittle material followed by $15 \mathrm{vol} . \%$ and 5 vol.\% $\mathrm{Al}_{2} \mathrm{O}_{3}$ MMC. In addition, [5] stated that three primary factors affecting the ductility of the composites: reinforcement strength, interface bond strength and matrix toughness. Any void created either by particle cracking or by interface failure can lead to a decrease in ductility. Displacement length as well indicates the ductility of the MMC sample. For 5 vol.\% $\mathrm{Al}_{2} \mathrm{O}_{3}$ $\mathrm{MMC}$ is the most ductile material followed by 15 vol.\% and $25 \mathrm{vol} . \% \mathrm{Al}_{2} \mathrm{O}_{3}$ MMC samples in descending order. This is agreed by [6] whereby ductility of the MMCs decreases with the increase in the volume fraction of particulate. 


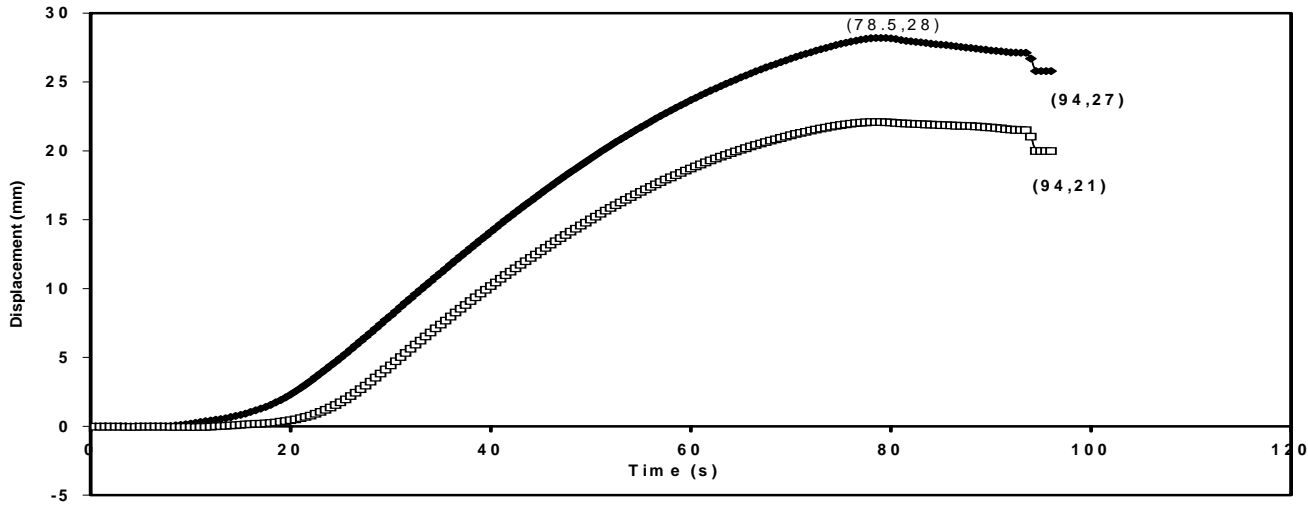

(a)

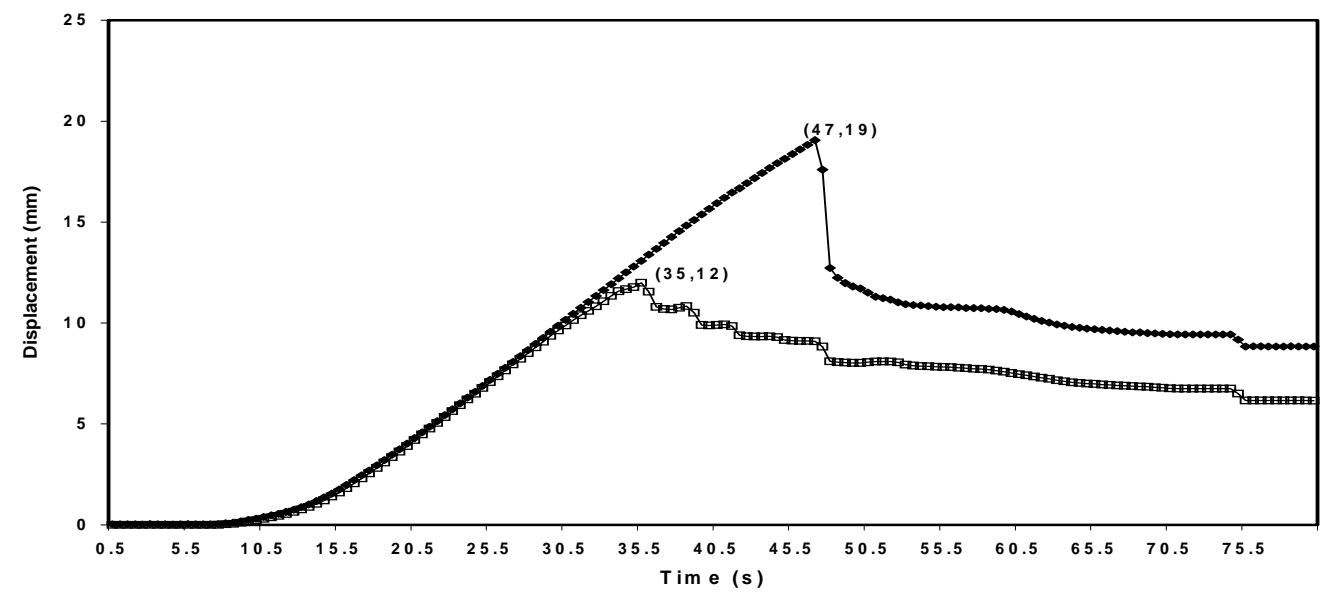

(b)

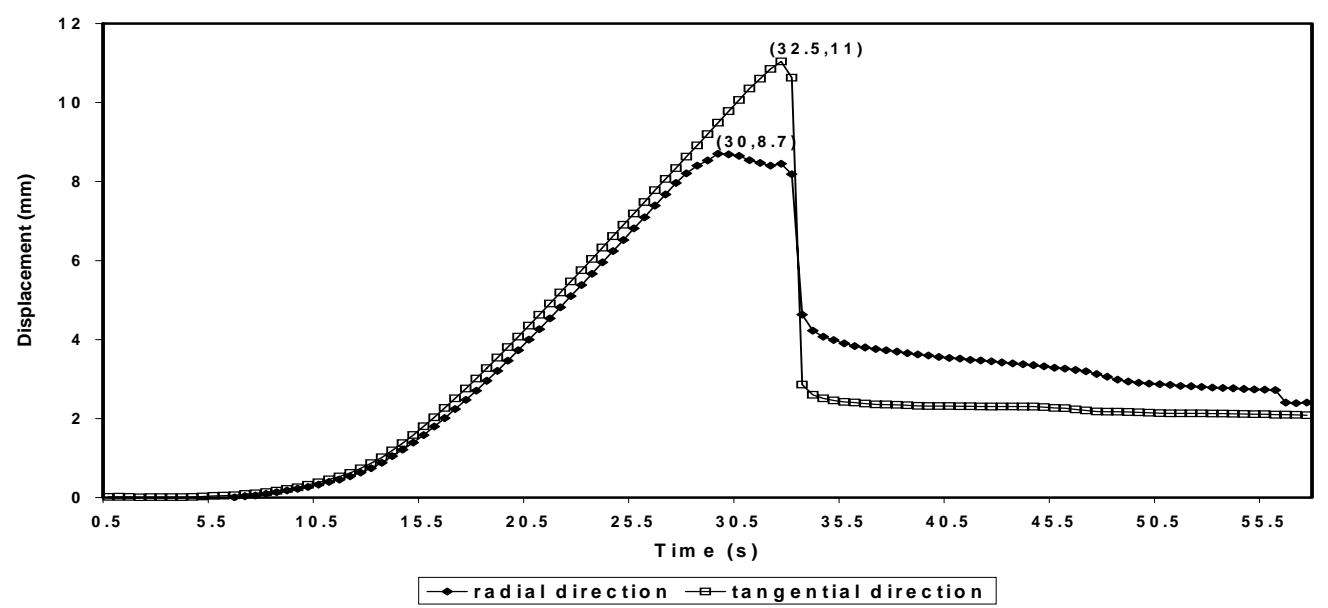

(c)

Fig. 8: Displacement verses time of the $M M C$ with, (a): 5 vol.\% of $\mathrm{Al}_{2} \mathrm{O}_{3}$; (b): $15 \mathrm{vol} . \% \mathrm{Al}_{2} \mathrm{O}_{3}$ and (c): 25 vol. $\% \mathrm{Al}_{2} \mathrm{O}_{3}$ 


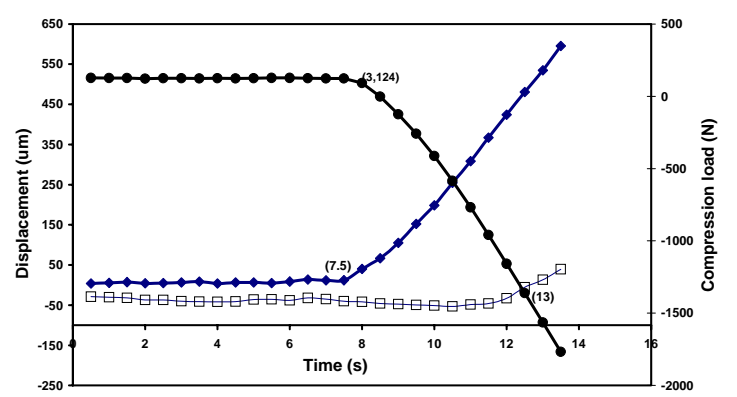

(a)

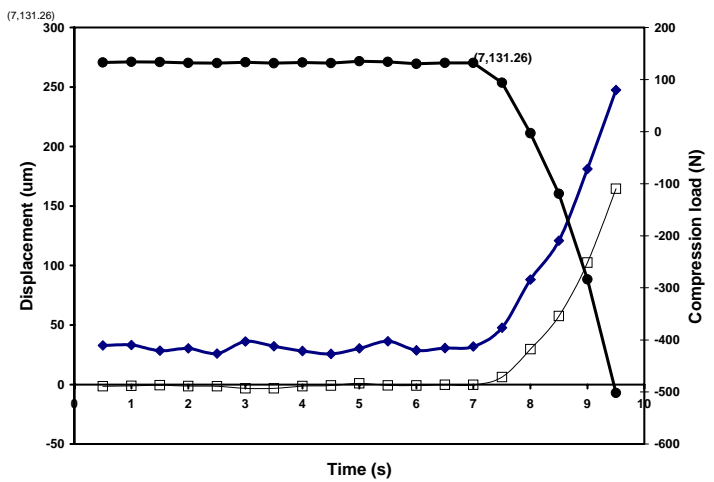

(b)

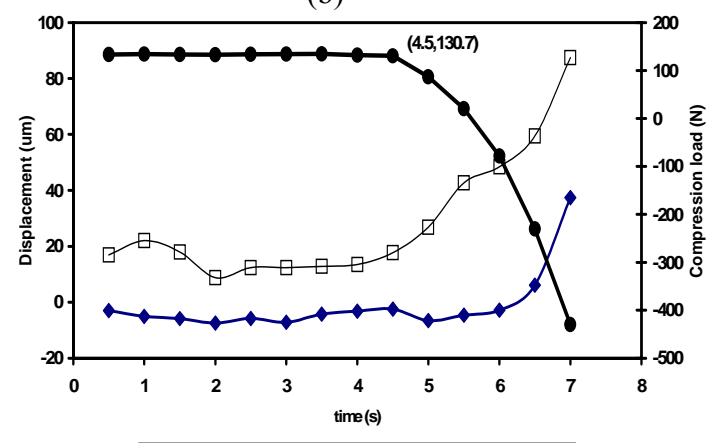

$\rightarrow$ radial direction $\rightarrow$ tangential direction $\rightarrow$-compression load

(c)

Fig. 9: Displacement and deformation load verses time at the initial stage of compression loading of the MMC with, (a): 5 vol. $\% \mathrm{Al}_{2} \mathrm{O}_{3}$; (b): 15 vol.\% $\mathrm{Al}_{2} \mathrm{O}_{3}$ and (c): 25 vol.\% $\mathrm{Al}_{2} \mathrm{O}_{3}$

\subsection{Microstructures analysis}

A study on the deformed MMC revealed that the small particles of $2 \mu \mathrm{m}$ in size were rarely fractured and less debonding at interface observed. However, for the particles of $5 \mu \mathrm{m}$ in size, some debonding at interfaces besides fractured particles have been observed. These findings were clearly observed in the samples of $5 \mathrm{vol} \% \mathrm{Al}_{2} \mathrm{O}_{3}$ where some of the particles were fractured with serious debonding interface as shown in Fig. 10(a). On the other hand, for 15 and 25 vol. $\% \mathrm{Al}_{2} \mathrm{O}_{3} \mathrm{MMC}$ sample, less fractured particles and fine debonding at interface were observed as illustrated in Figs. 10(b) and (c), minor fractured particles and debonding at interface have been observed. 


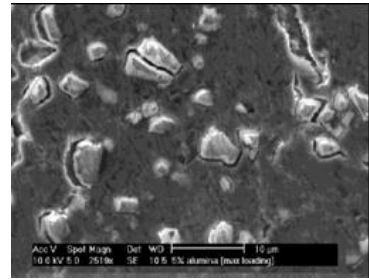

(a)

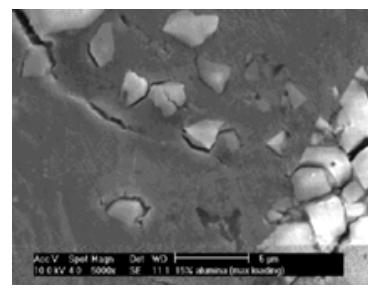

(b)

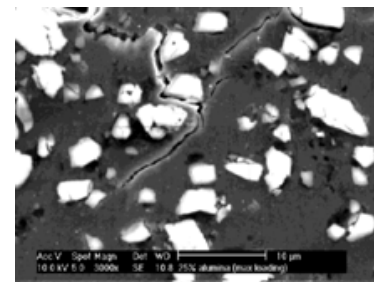

(c)

Fig. 10: Individual small particles of the MMC after deformation test with; (a): 5 vol.\% $\mathrm{Al}_{2} \mathrm{O}_{3}$; (b): $15 \mathrm{vol} . \% \mathrm{Al}_{2} \mathrm{O}_{3}$ and (c): $25 \mathrm{vol} . \% \mathrm{Al}_{2} \mathrm{O}_{3}$

A study on the individual large particle of all the deformed MMC samples shows that the particles of $20 \mu \mathrm{m}$ in size and above are badly fractured and some parts of the particles are missing. Figure 11(a) shows the behaviour of the large particles in 5 vol.\% $\mathrm{Al}_{2} \mathrm{O}_{3} \mathrm{MMC}$ samples. Cracks at the edge of the particles, particles pulled out and debonding interface of the large particles have been observed. Short microcracks were propagated from the interface of the particles to the matrix. Figure 11(b) illustrates the large particles of 15 vol. $\% \mathrm{Al}_{2} \mathrm{O}_{3} \mathrm{MMC}$ samples, serious cracks with particles pulled out were observed on the large particles. Short and long microcracks were branching out from the interface of the particles to the matrix. For 25 vol. $\% \mathrm{Al}_{2} \mathrm{O}_{3} \mathrm{MMC}$ samples as illustrated in Fig. 11(c), large particles were seriously fractured and particle pulled out were observed. There were minor microcracks observed around the interface of the particles.

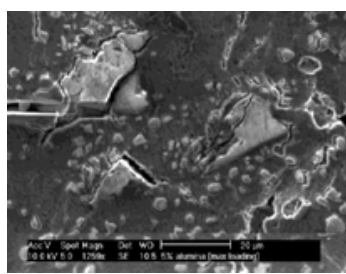

(a)

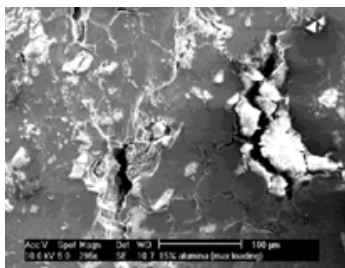

(b)

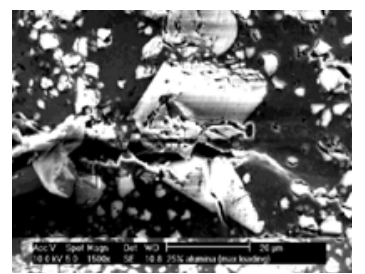

(c)

Fig. 11: Individual large particles of the MMC after deformation test with; (a): 5 vol.\% $\mathrm{Al}_{2} \mathrm{O}_{3}$; (b): 15 vol.\% $\mathrm{Al}_{2} \mathrm{O}_{3}$ and (c): 25 vol.\% $\mathrm{Al}_{2} \mathrm{O}_{3}$

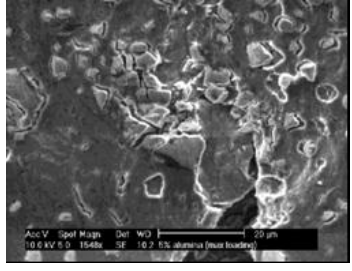

(a)

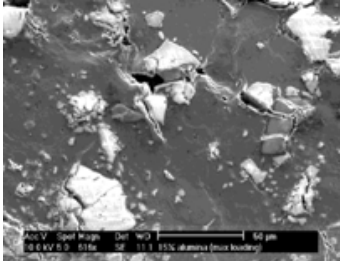

(b)

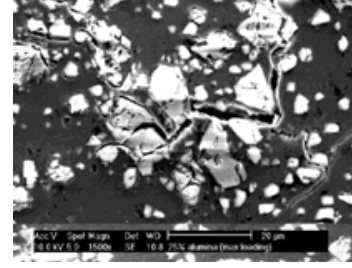

(c)

Fig. 12: Small cluster in the MMC after deformation test with; (a): 5 vol.\% $\mathrm{Al}_{2} \mathrm{O}_{3}$; (b): $15 \mathrm{vol} \%$ $\mathrm{Al}_{2} \mathrm{O}_{3}$ and (c): 25 vol.\% $\mathrm{Al}_{2} \mathrm{O}_{3}$ 
Analyses on the small clusters have been performed to all the MMC samples. Figure 12 shows the behaviour of small cluster in the MMCs. For 5 vol.\% $\mathrm{Al}_{2} \mathrm{O}_{3} \mathrm{MMC}$ sample, particle pulled out and debonding at interface of the individual particles within the cluster were observed as illustrated in Fig. 12(a). Similarly cracks have been observed in 15 vol. $\% \mathrm{Al}_{2} \mathrm{O}_{3} \mathrm{MMC}$ sample as shown in Fig. 12(b). Voids indicate the particles pulled out and short microcracks were propagated from the interface of the individual particle within the cluster and ended at the matrix. Severe cracks have been observed in the 25 vol. $\% \mathrm{Al}_{2} \mathrm{O}_{3} \mathrm{MMC}$ samples as shown in Fig. 12(c). The cracks were propagated through the small cluster, along the interface of the individual particle within the small cluster and ended at the matrix.

Figure 13 reveals the large cluster of the MMC samples. For 5 vol. $\% \mathrm{Al}_{2} \mathrm{O}_{3} \mathrm{MMC}$ sample as shown in Fig. 13(a), the large cluster consist of individual small particles. Microcracks were propagated along the outermost region of the cluster and there was no microcrack propagated though the cluster. Fine microcracks were branching out from the outermost region of the cluster to the matrix. Similarly, for 15 vol. $\% \mathrm{Al}_{2} \mathrm{O}_{3}$ MMC sample as illustrated in Fig. 13(b), microcracks propagated along the edge of the clusters, then extended along the interface of the individual particle at the edge of the cluster and ended at the matrix. Intergranular microcracks and debonding interface of the individual particle were observed only along the edge of the cluster. There have been no debonding interface and microcracks observed at the centre of the cluster. Similarly, in 25 vol.\% $\mathrm{Al}_{2} \mathrm{O}_{3} \mathrm{MMC}$ sample as illustrated in Fig. 13(c), debonding interface and intergranular crack were only propagated along the edge of the cluster and ended at the matrix.

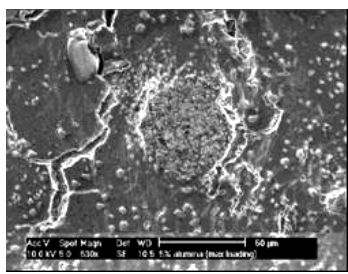

(a)

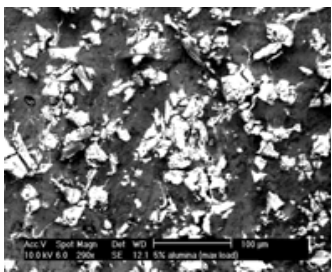

(b)

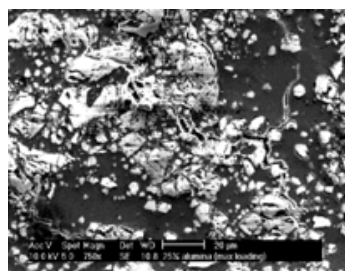

(c)

Fig. 13: Large cluster in the MMC after deformation test with; (a) 5 vol.\% $\mathrm{Al}_{2} \mathrm{O}_{3}$, (b) $15 \mathrm{vol. \%}$ $\mathrm{Al}_{2} \mathrm{O}_{3}$ and (c) 25 vol.\% $\mathrm{Al}_{2} \mathrm{O}_{3}$

Generally for 5 vol. $\%, 15$ vol. $\%$ and 25 vol. $\% \mathrm{Al}_{2} \mathrm{O}_{3}$ MMC samples most of the small particles of $2 \mu \mathrm{m}$ in size exhibit strong interfacial bonding. There are almost no cracks and debonding interface at the small particles. As stated by [7], during the deformation process, load is transferred from the matrix to the particles, leading to an increase in flow-stress at the interfaces between the ductile matrix and the rigid particles. The interfacial bonding between the small particles and the matrix is very strong and is able to transfer high deformation loading without fracture. On the other hand, interfacial debonding is more pronounced in most of the small particles of $5 \mu \mathrm{m}$ in size. Debonding interface is promoted by a weak interface between the particle and the matrix as revealed by [8]. Large ceramic particles are more likely to fracture rather than small particles because of their critical size. The total interfacial area of the small particle is high, thus interfacial failure is more significant in the particle. The small particle requires high stresses for internal damage to occur as compared to the large particle. Therefore, when the applied stress reaches the yield stress of the matrix materials, most of the small particles will still be intact. These explanations are very much agreed by the result finding whereby debonding interface is only pronounced in 5 vol.\% and 15 vol. $\% \mathrm{Al}_{2} \mathrm{O}_{3}$ MMC. At 25 vol. $\% \mathrm{Al}_{2} \mathrm{O}_{3} \mathrm{MMC}$ the outstanding defect are the fractured particles and the pulled out particles. 


\subsection{Microstructures and stresses relationship}

Figure 14 illustrates a schematic diagram of the possible fracture behaviour of small and large particles at the initial stage of deformation loading. At the initial stage of the deformation loading the particles experience both tangential and radial stresses. The radial stress tends to pull the particle to the radial direction, while the tangential stress tends to move along the interface of the particle [9]. For the small particle, as illustrated in the microstructures and the schematic diagram, the debonding at interface of the particle is due probably to the tangential stress. On the other hand, the large particle may experience high radial stress thus the particle is prone to fracture.

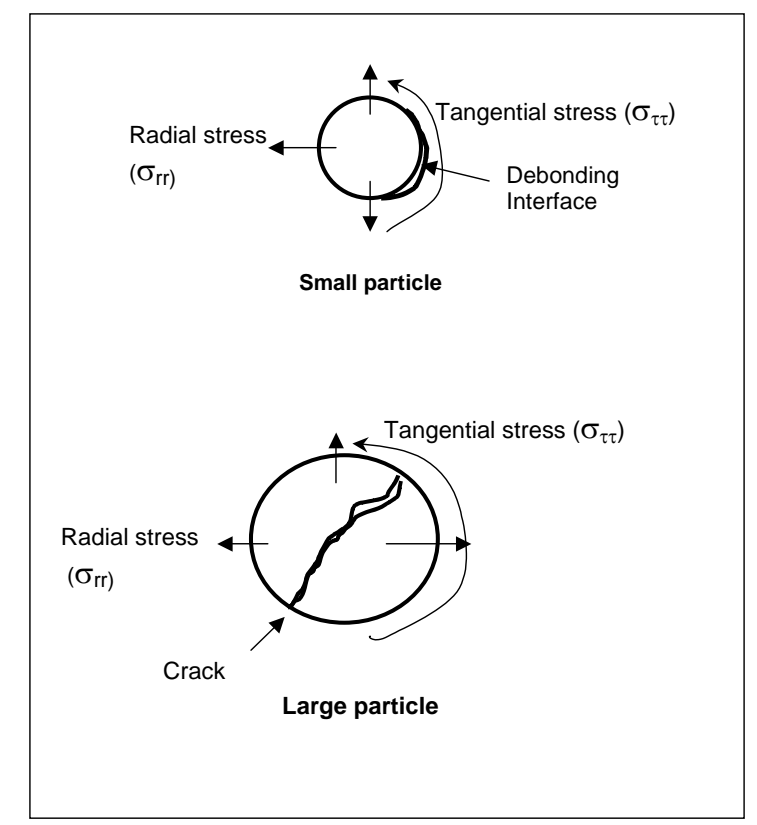

Fig. 14: Schematic diagram of the possible fracture behaviour of the small and large particle at the initial stage of the deformation loading of the MMCs

Figure 15 illustrates schematic diagram of the possible fracture behaviour of the large and small clusters. The effects of radial and tangential stresses introduce fractured particles, debonding interface and microcrack in the small clusters. For the large cluster, distribution of the radial stress is very high at the outermost region of the large cluster as compare to the centre region. This radial stress is released by the formation of cracks or debonding interface of the particles at the edge of the large clusters. The effect of tangential stress extends along this critical path at the outermost region of the large cluster and hence introduces microcracks at the edge of the large cluster. This is explained by [7] and [10], by saying that within the cluster, all the stresses are transferred from the matrix to the particles which fracture when these stresses reach critical values. If the matrix ductility can be restored there will be no fracture in the cluster. The material is thus able to let the stress flow to the particle without fracture. From the observation on the microcracks within the small clusters, the microcracks could be initiated from the centre of the small cluster, propagated across the particles, extended along the interface of the particle before they ended at the matrix. This discovery is admitted by [11], whereby damage in the particles cluster is in the form of cracked particles and voids, which have formed around the particles. The fracture initiates by particles cracking coupled with decohesion of the matrix surrounding and between the particulate reinforcements. Final fracture is achieved by damage propagation through the matrix between particle-rich regions. The cracks initiated both at and 
near particle matrix particle-matrix interfaces in regions of particle agglomeration. In particulate-rich regions of the matrix, fracture occurs early and the damage propagates rapidly among the reinforcing particle agglomerate. In addition, [12] added that the higher the volume fraction of reinforcement particles, the more the local clustering or agglomeration of particles occurs. Therefore, there is a limit on the volume fraction of reinforcement added in order to achieve good ductility.

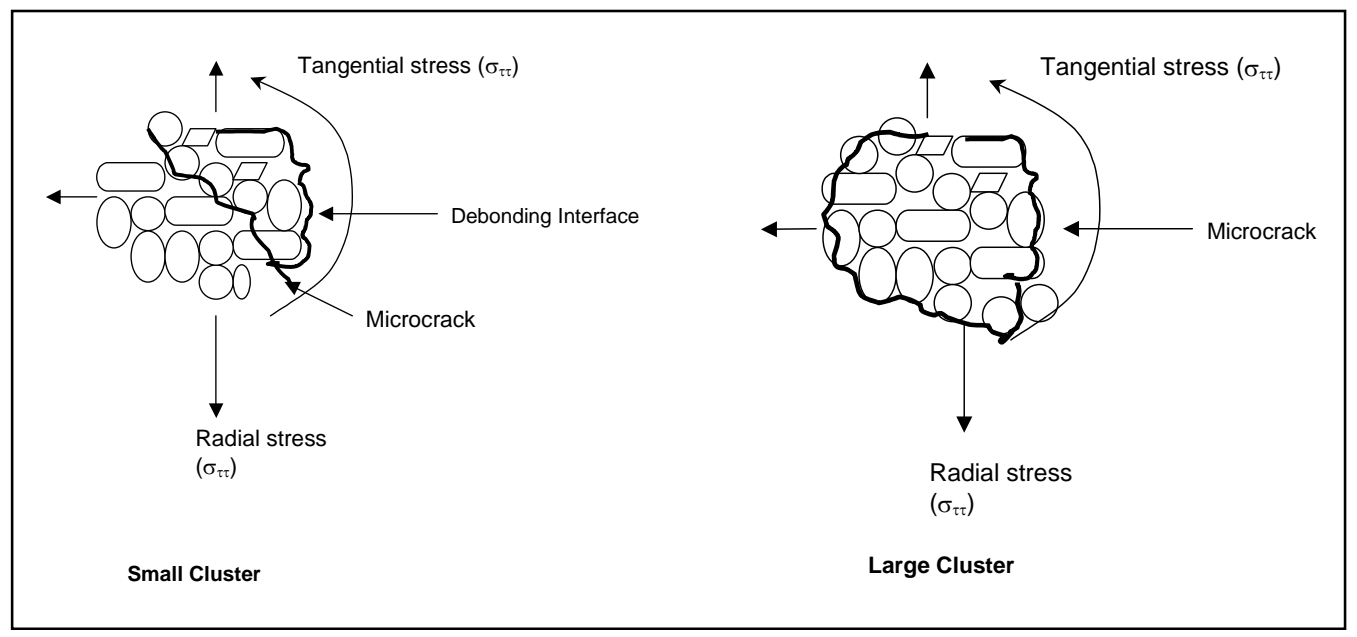

Fig. 15: Schematic diagram of the possible fracture behaviour of the small and large cluster at the latter stage of the deformation loading of the MMCs

Since the radial stress seems to dominate the fracture initiation of 5 vol.\% and 15 vol.\% $\mathrm{Al}_{2} \mathrm{O}_{3}$ MMC samples, assumption can be made that the large particles fracture and small cluster defect are the most common incidences in the fracture initiation of the MMCs. In view of the fact that tangential stress dominates the fracture initiation of the $25 \mathrm{vol} . \% \mathrm{Al}_{2} \mathrm{O}_{3} \mathrm{MMC}$, suggestion can be made that the debonding interface of the large particle is also the most common defect in the fracture initiation of the MMCs. Finally at the latter stage of the fracture process, all the particles and the clusters are involved in creating the fracture behaviour of the MMCs.

\section{CONCLUSIONS}

- In the deformed 5 vol.\% $\mathrm{Al}_{2} \mathrm{O}_{3}$ MMC samples, debonding interface and fractured particles are the most common occurrence in the fracture initiation. This happens with less domination from the small and large clusters. The fracture initiation of the MMC samples is more towards the radial direction.

- From the deformed 15 vol.\% $\mathrm{Al}_{2} \mathrm{O}_{3}$ MMC samples, the fracture behaviour of the MMC is influenced by the fractured particles and the deformed small clusters with less influence from the large clusters. The fracture initiation of the MMC samples is more towards the radial direction.

- From the test results of the 25 vol.\% $\mathrm{Al}_{2} \mathrm{O}_{3}$ MMC samples, fracture behaviour of the MMC samples is influenced by the fractured and pulled out particles, and the deformed small cluster. There is less influence from the small particles and the large clusters. The tangential stress dominates the fracture initiation of the MMC samples. 
- Generally for 5 vol. $\%, 15$ vol.\% and 25 vol.\% $\mathrm{Al}_{2} \mathrm{O}_{3}$ MMC samples most of the small particle of $2 \mu \mathrm{m}$ in size exhibit strong interfacial bonding. On the other hand, decohesion is the most common scenario when small particles of $5 \mu \mathrm{m}$ in size is used. Large particles of 20 $\mu \mathrm{m}$ in size and above are seriously fractured even at the low deformation loading.

- The effects of radial and tangential stresses introduce fractured particles, debonding interface and microcracks in the small clusters. For large clusters, distribution of the radial stress is very high at the outermost region of the large cluster as compared to the centre region. This radial stress is released by the formation of intergranular crack and debonding interface at the edge of the large clusters. The effect of tangential stress extends along this critical path on the outermost region of the large cluster and hence introduces microcracks at the edge of the large cluster. The clusters are only affected by high deformation loading.

- From the microstructure study of the undeformed and deformed samples, from the value of the sample displacement obtained during the deformation test and from the mechanical properties obtained deformed MMCs samples, one can finally understand some of the fracture behaviour exhibited by $\mathrm{Al} 6061 \mathrm{MMC}$ reinforced with different vol. $\%$ of $\mathrm{Al}_{2} \mathrm{O}_{3}$.

\section{ACKNOWLEDGEMENT}

The authors would like to express their gratitude and sincere appreciation to the Institute of Research and Commercialisation, Universiti Teknologi MARA, Project No. 600IRDC/ST.5/3/640 and Faculty of Chemical Engineering, Universiti Teknologi MARA for supporting the group in undertaking the research project.

\section{REFERENCES}

1. Ford, T.T. (1997), Aerospace Composites, Aircraft Engineering and Aerospace Technology, vol. 69(4), pp. 334-342.

2. Lequeu, P., Lassince, P., Warner, T., and Raynaund, G.M. (2001), Engineering for the Future: Weight Saving and Cost Reduction Initiatives, Aircraft Engineering and Aerospace Technology, vol. 73(2), pp. 147-159.

3. Kennedy, A.R. and Wyatt, S.M. (2000), The Effect of Processing on the Mechanical Properties and Interfacial Strength of Aluminium /TiC MMCs, Composites Science and Technology, vol. 60, pp. 307-314.

4. Gnjidic, Z., Božić, D., and Mitkov, M. (2001), The Influence of SiC Particles on the Compressive Properties of Metal Matrix Composites, Materials Characterization, vol. 47, pp. 129-138.

5. Kapoor, R. and Vecchio, K.S. (1995), Deformation Behavior and Failure Mechanism in Particulate Reinforced 6061 Al Metal-Matrix Composites, Materials Science and Engineering, vol. A202, pp. 63-75.

6. Doel, T.J.A. and Bowen, P. (1996), Tensile Properties of Particulate-Reinforced Metal Matrix Composites, Composites: Part A, vol. 27, pp. 655-665.

7. Cavaliere, P. (2004), Isothermal Forging of AA2618 Reinforced with $20 \%$ of Alumina Particles, Composites: Part A, vol. 35, pp. 619-629.

8. Davies, C.H.J., Raghunathan, N., and Sheppard, T. (1992), Structure-Property Relationships of $\mathrm{SiC}$ Reinforced Advanced Al-Zn-Mg-Cu Alloy, Material Science and Technology, vol. 8, pp. 977-984. 
9. Miao, X. (2003), Observation of Microcracks Formed in HA-316L Composites, Materials Letter, vol. 57, pp. 1848-1853.

10. Hu, G.K., Guo, G., and Baptiste, D. (1998), A Micromechnical Model of Influence of Particle Fracture and Particle Cluster on Mechanical Properties of Metal Matrix Composite, Computational Materials Science, vol. 9, pp. 420-430.

11. Srivatsan, T.S. (1996), Microstructure, Tensile Properties and Fracture Behaviour of $\mathrm{Al}_{2} \mathrm{O}_{3}$ Particulate-Reinforced Aluminium Alloy Metal Matrix Composites, Journal of Materials Science, vol. 31, pp. 1375-1388.

12. Tang, F., Anderson, I.E., and Biner, S.B. (2003), Microstructures and Mechanical Properties of Pure Al Matrix Composites Reinforced by Al-Cu-Fe Alloy Particles, Materials Science and Engineering, vol. A363, pp. 20-29. 